\title{
The role of nutrients in meat flavour formation
}

\author{
BY LINDA J. FARMER \\ Department of Agriculture for Northern Ireland, Food and Agricultural Chemistry Research \\ Division, and The Queen's University of Belfast, Newforge Lane, Belfast BT9 5PX
}

'The role of meat in the human diet' addresses a very broad subject, covering the nutritional, social, economic and gustatory aspects of meat eating. Although meat is an important source of nutrients, this is probably not the reason why most people eat it; those who eat meat do so because they like the characteristic aroma, flavour and texture. However, the nutritional aspects of meat and its flavour are related, as many of the nutrients in meat are also involved in flavour formation.

Flavour, whether of meat or any other food, comprises mainly the two sensations of taste and smell, although other sensations such as astringency, mouthfeel and juiciness may also play a part. Receptors in the mouth can recognize four main taste sensations (sweet, salt, sour and bitter). In contrast, many hundreds or even thousands of different odours can be distinguished by the human nose. The sensation of odour is produced by volatile chemical substances which stimulate the receptors in the nasal epithelium. Odour compounds may reach these receptors either through the nose (by smelling) or through the posterior nares at the back of the nose and throat while food is being chewed in the mouth. Thus, odour plays a major part in defining the characteristic flavour of a food.

\section{SUBSTANCES IN MEAT RESPONSIBLE FOR TASTE AND ODOUR}

While odour is generally caused by low-molecular-weight volatile compounds, taste substances are usually much larger and water soluble. A further class of non-volatile components, known as flavour enhancers, do not necessarily possess a taste or aroma themselves but enhance the flavour of other compounds.

\section{Taste compounds}

These are non-volatile or water-soluble compounds with taste or tactile properties, including inorganic salts and sodium salts of certain acids (salty), hypoxanthine, peptides and some amino acids (bitter), sugars and some amino acids (sweet) and acids (sour) (Moody, 1983).

\section{Flavour enhancers}

These increase the deliciousness or savouriness of a food (known as 'umami' in Japanese) and include $\mathrm{L}$-amino acids containing five $\mathrm{C}$ atoms and certain $5^{\prime}$-nucleotides. The most important flavour enhancers in meat are glutamic acid, monosodium glutamate and inosinic acid (Moody, 1983; Shahidi et al. 1986). 


\section{Odour compounds}

There are thousands of low-molecular-weight compounds which can give rise to odour sensations; these include both aliphatic and aromatic compounds which generally contain a heteroatom $(\mathrm{O}, \mathrm{N}, \mathrm{S})$. This confers a precise electronic configuration which is recognizable by the nasal receptors. Such compounds can arise from a variety of sources. In raw fruit and vegetables aroma compounds are formed by enzymic action during ripening. Enzymic action, also, can be responsible for the fermentation of unpleasant odours in meat and other foods, whether due to microbiological spoilage or the metabolism of the animal; off-flavours can also arise due to autoxidation of lipids or external contamination (Saxby, 1993). However, in cooked foods many of the volatile compounds are formed by chemical reactions caused by heating; in the case of cooked meats these reactions are the main source of odour compounds (Mottram, 1991).

While many of the taste compounds also have a nutritional function, aroma compounds have almost no nutritional value as only very low quantities are present in meat. However, these aroma compounds are formed by reactions occurring during the cooking process and most of the precursors of these reactions are nutritional components of meat.

More than 800 volatile compounds have been identified in cooked beef aroma (Maarse, 1989). However, it is believed that a relatively small number of compounds actually play an important part in the overall aroma of cooked meat. Whether a compound is one of these key odour impact compounds depends on both its concentration and its odour threshold, i.e. how sensitive the human nose is to that particular compound. Table 1 lists some of the most important aroma compounds in cooked beef; individually, they have odours as shown, but together they give cooked beef aroma. Probable routes of formation of these compounds are also given: trans-2-rionenal, trans,trans-2,4-decadienal and 1-octen-3-one may be derived from the thermal oxidation of polyunsaturated fatty acids; methional, phenylacetaldehyde and 2-acetyl-1-pyrroline are products of the Maillard reaction between amino acids and reducing sugars (the first

Table 1. Important odour compounds in cooked beef

\begin{tabular}{|c|c|c|c|}
\hline Compound & Odour & Precursor(s) & Mechanism \\
\hline Trans-2-nonenal* & Tallowy, fatty & $n-6$ Fatty acids & Thermal oxidation \\
\hline Trans,trans-2,4-decadienal* & Fatty, fried potato & $n-6$ Fatty acids & Thermal oxidation \\
\hline 1-Octen-3-one ${ }^{*}$ & Mushrooms & $n-6$ Fatty acids & Thermal oxidation \\
\hline 2-Acetyl-1-pyrroline* & Roasty, sweet & Proline $\dagger$ & Maillard reaction \\
\hline Methional* & Cooked potato & Methionine & Strecker degradation \\
\hline Phenylacetaldehyde* & Honey-like, sweet & Phenylalanine & Strecker degradation \\
\hline 2-Methyl-3-furanthiol* & $\begin{array}{l}\text { Meat-like, sweet, } \\
\text { sulphurous }\end{array}$ & $\begin{array}{l}\text { Cysteine and ribose } \\
\text { or }\end{array}$ & Maillard reaction \\
\hline Bis 2-methyl-3-furyl disulphide* $*$ & Meat-like, oxo & Thiamin & Thermal degradation \\
\hline $\begin{array}{l}\text { 2-Methyl-3-turyl 2-furturyl } \\
\text { disulphide }\end{array}$ & Roasted, meat-like & & \\
\hline$\beta$-Ionone* & Violet-like & $\beta$-Carotene & Oxidative degradation \\
\hline
\end{tabular}


two are formed by the Strecker degradation of the amino acids methionine and phenylalanine respectively); $\beta$-ionone is probably formed from the oxidative breakdown of $\beta$-carotene from the diet (Gasser \& Grosch, 1988). The furyl disulphides can be formed either by the Maillard reaction between cysteine and reducing sugars or from the breakdown of thiamin (vitamin $B_{1}$ ); these compounds will be discussed in more detail in the following section.

While there are aspects of the formation of these compounds which remain unclear, it is apparent that two reactions are of particular importance in meat aroma formation: the Maillard reaction and the oxidation of lipids during heating.

\section{THE MAILLARD REACTION BETWEEN SUGARS AND AMINO ACIDS}

The Maillard reaction between amino acids (or peptides) and reducing sugars is important for flavour formation in many cooked foods. This reaction is a complex network of reactions which yields both high-molecular-weight brown-coloured products and volatile aroma compounds. The Maillard reaction has been extensively reviewed (for example, see Hurrell, 1982). The reaction between one amino acid and one sugar will yield hundreds of volatile compounds (Salter et al. 1988; Farmer et al. 1989). These include a range of heterocyclic compounds, in which a ring structure contains an atom of $\mathrm{N}$, O or $\mathrm{S}$, depending on the heteroatoms present in the amino acid. The odour obtained from such reactions is also dependent on the amino acid, while the nature of the sugar dictates the rate of the reaction (Kiely et al. 1960). In the case of cooked meat, the S-containing amino acids have particular relevance, especially cysteine (Kiely et al. 1960; Morton et al. 1960). Reactions of this type have been patented for use as synthetic meat flavourings (MacLeod \& Seyyedain-Ardibili. 1981).

The compounds found to be of particular importance for artificial 'meaty' flavours are the furan and thiophene thiols and disulphides (MacLeod, 1986). They have in common a furan or thiophene ring with a thiol group in the 3-position; this gives a 'meaty' aroma, while similar compounds with a thiol in the 2-position tend to be 'burnt' and 'sulphurous'. The best meat-like aroma is given when there is a methyl group adjacent to the thiol group and the ring contains at least one double bond (van den Ouweland et al. 1989). A number of compounds of this type have now been identified in cooked meats (Gasser \& Grosch, 1988, 1990; Farmer \& Patterson, 1991; Mottram \& Madruga, 1993). The use of odour dilution techniques has demonstrated that 2-methyl-3-furanthiol, bis 2-methyl-3furyl disulphide and 2-methyl-3-furyl 2-furfuryl disulphide are among the most important contributors to beef flavour while 2-methyl-3-furanthiol and 2,5-dimethyl-3-furanthiol are important odour compounds in chicken (Fig. 1). The formation of some of these compounds has been shown to depend on $\mathrm{pH}$ and this may explain the known $\mathrm{pH}$ dependency of meat flavour (Farmer \& Mottram, 1990b).

Furanthiols and their disulphides can be formed from either the Maillard reaction between cysteine and a reducing sugar (Farmer et al. 1989; Farmer \& Mottram, 1990b) or from the thermal degradation of thiamin (van den Ouweland \& Peer, 1975). Which of these mechanisms is most important in meat itself remains the subject of research (Grosch et al. 1993; Mottram \& Madruga, 1993). In model systems, both the Maillard reaction and the breakdown of thiamin produce a wide range of odorous compounds (MacLeod \& Seyyedain-Ardibili, 1981; Mottram, 1991). 


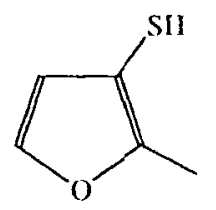

A

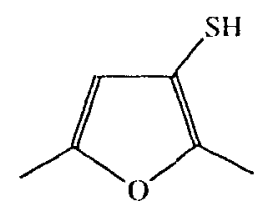

C

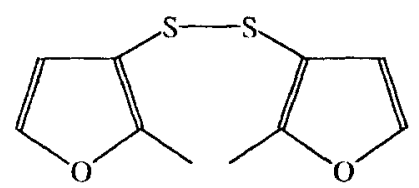

B

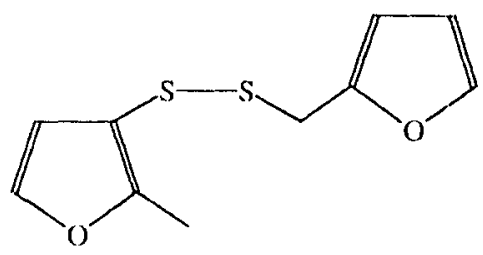

D

Fig. 1. Furanthiols and disulphides important in meat flavour: (A), 2-methyl-3-furanthiol; (B), bis 2-methyl-3furyl disulphide; (C), 2,5-dimethyl-3-furanthiol; (D), 2-methyl-3-furyl 2-furfuryl clisulphide.

\section{LIPID OXIDATION}

Lipids can break down via oxidation of the fatty acids to give volatile odour compounds which contribute to both desirable and undesirable flavours (Mottram, 1987). At room temperature and even, to a lesser extent, at refrigeration and freezer temperatures, autoxidation of lipids can occur to give rancidity in raw meat or 'warmed-over flavour' in stored cooked meat. However, the heating of lipids (as in cooking) gives rise to thermal oxidation reactions which, although they follow very similar pathways to autoxidation, give slightly different products and contribute to the desirable flavour formed during cooking; the balance between the many pathways which make up lipid oxidation is affected by the application of heat.

The oxidation of lipids gives a wide range of aliphatic products, including both saturated and unsaturated hydrocarbons, alcohols, aldehydes, ketones, acids and esters as well as some cyclic compounds (such as furans, lactones and cyclic ketones). Many of these possess intense odours and contribute to the overall aromas of many different kinds of foods (Forss, 1972).

Polyunsaturated fatty acids are much more susceptible to oxidation than monounsaturated or saturated fatty acids and some of the key odour impact compounds in meat are derived from polyunsaturated fatty acids (Gasser \& Grosch, 1988). Of the different classes of lipids present in meat, phospholipids have a high level of unsaturation and so are particularly vulnerable to oxidation. It is thought that the oxidation of phospholipids is not only important for 'warmed-over flavour' but that they also play a significant part in the formation of desirable meat flavour. Evidence for this was obtained by extracting either the triacylglycerols only, or the total lipids (including the phospholipids), from meat (Mottram \& Edwards, 1983). A study of the aroma volatiles showed that removal of the triacylglycerols had little effect on either the aroma of the cooked meat or on the pattern of volatile compounds observed using GLC-mass 
spectrometry. However, when the phospholipids were removed as well, the 'meaty' character of the aroma was lost and there was a marked alteration in the volatile products. It appeared that phospholipids (but not triacylglycerols) were important for meat flavour formation. In addition, the nature of the changes in volatile compounds suggested that the route by which phospholipids promote meat flavour may involve their participation in the Maillard reaction.

Further work confirmed these effects using model systems (Whitfield et al. 1988; Farmer \& Mottram, 1990a). The exact mechanism by which phospholipids improve meaty aroma is not yet known, but it has been established that lipid oxidation and the Maillard reaction do not occur in isolation and that interactions between these two pathways can cause a wide range of effects on the volatile aroma compounds produced (Farmer \& Mottram, 1990a, 1992, 1993). The presence of amino acids and sugars can reduce the amounts of potent odorous products of the lipid oxidation reactions, and the presence of lipids can likewise reduce the quantities of some Maillard products. In addition, the interaction of these two reactions also gives a new range of aroma compounds which depend on both reactions for their formation. Thus, an alteration to one precursor can affect the products of several reaction pathways. For example, the level of unsaturation of fatty acids and the precise structures of phospholipids have a large effect not only on the products of lipid oxidation but also on the way that these components affect the Maillard reaction (Farmer \& Mottram, 1993).

One example of a link between lipid composition and flavour is that of grass-fed $v$. concentrate-fed beef. It has been suggested that the flavour of concentrate-fed beef is preferred, with the flavour of grass-fed beef having 'milky', 'grassy' notes (Melton et al. 1982; Melton, 1983). Compared with grass-fed beef, phospholipids from grain-fed cattle contain more $n-6$ fatty acids and less $n-3$ fatty acids; this is thought to be due to the high content of $n-3$ fatty acids in forage grasses, whereas maize contains high levels of $n-6$ fatty acids (Melton, 1983; Marmer et al. 1984). These classes of fatty acids give different oxidation products as a result of the different positions of their double bonds; as they are polyunsaturated they are also very reactive for flavour formation. Grass-fed beef has higher levels of low-molecular-weight aldehydes (Larick \& Turner, 1990) and some of these possess 'grassy' odours; these compounds may arise from thermal oxidation of the $n-3$ fatty acids. This suggests that the balance of $n-6$ and $n-3$ fatty acids in the phospholipids is important for flavour formation.

The characteristic flavours of different species' meats are also thought to be related to lipid composition. Lamb, pork, chicken and beef have more or less clearly distinguishable aromas. The compounds responsible for these characteristic species notes are not all known. However, those that are known appear to be lipid-derived. For example, in chicken, trans,trans-2,4-decadienal is thought to give the characteristic species note (Pippen \& Nonaka, 1960; Gasser \& Grosch, 1990), while for lamb various branchedchain fatty acids confer the characteristic flavour (Wong et al. 1975). For beef, recent work has suggested that a branched-chain aldehyde (12-methyltridecanal) derived from the plasmalogen forms of phospholipids may be important (Grosch et al. 1993).

Not only can the precise composition of lipids affect the formation of aroma compounds but so can any meat component capable of influencing the progress of lipid oxidation reactions. For example, vitamin $\mathrm{E}$, which is present naturally in meat, has an antioxidative effect. Morrissey (1993) has described how alterations in the levels of vitamin $\mathrm{E}$ affect the development of rancidity in uncooked meat and there is some 
evidence that such substances may also affect the formation of aroma compounds during cooking (Laksesvela, 1960). This is an area which requires further attention.

The presence of metal ions, on the other hand, can promote these lipid oxidation reactions and a great deal of work has been done on the effect of $\mathrm{Fe}^{3+}$ and haem groups on the formation of 'warmed-over flavour' (Rhee, 1988) and there is some evidence that $\mathrm{Cu}^{2+}$ may affect the formation of lipid oxidation products in cooked chicken (Ishida \& Kaji, 1981).

\section{CONCLUSION}

Substances in raw meat of particular importance for flavour-forming reactions during cooking include free amino acids, peptides, sugars and also phospholipids and their fatty acids, while various vitamins and minerals can alter the rate and extent of these reactions. The amounts and proportions of these compounds will dictate the progress of flavour-forming reactions and, hence, the ultimate flavour of the cooked meat. In addition, salts, acids, sugars and other soluble substances contribute to the taste of the meat. Thus, any change in the composition of nutrients in meat (or any other food) could lead to a change in the balance of flavour-forming reactions occurring and, therefore, to a change in the overall aroma and flavour.

\section{REFERENCES}

Farmer, L. J. \& Mottram, D. S. (1990a). The interaction of lipid in the Maillard reaction between cysteine and ribose: the effect of triglyceride and three phospholipids on the volatile products. Journal of the Science of Food and Agriculture 53, 505-525.

Farmer, L. J. \& Mottram, D. S. (1990b). Recent studies on the formation of meat-like aroma compounds. In Flavour Science and Technology, pp. 113-116 [Y. Bessiere and A. F. Thomas, editors]. Chichester: John Wiley and Sons.

Farmer, L. J. \& Mottram, D. S. (1992). Effect of cysteine and ribose on the volatile thermal degradation products of a triglyceride and three phospholipids. Journal of the Science of Food and Agriculture 60 , $489-497$.

Farmer, L. J. \& Mottram, D. S. (1994). Lipid-Maillard interactions in the formation of volatile aroma compounds. In Trends in Flavour Research, pp. 313-326 [H. Maarse and D. J. van der Heij, editors]. Amsterdam: Elsevier.

Farmer, L. J., Mottram, D. S. \& Whitfield, F. B. (1989). Volatile compounds produced in Maillard reactions involving cysteine, ribose and phospholipid. Journal of the Science of Food and Agriculture 49, 347-368.

Farmer, L. J. \& Patterson, R. L. S. (1991). Compounds contributing to meat flavour. Food Chemistry 40, 201-205

Forss, D. A. (1972). Odor and flavor compounds from lipids. Progress in the Chemistry of Fats and other Lipids 13. $181-258$.

Gasser, U. \& Grosch, W. (1988). Identification of volatile flavour compounds with high aroma values from cooked beef. Zeitschrift für Lebensmittel-Untersuchung und Forschung 186, 489-494.

Gasser, U. \& Grosch, W. (1990). Primary odorants of chicken broth: a comparative study with meat broths from cow and ox. Zeitschrift für Lebensmittel-Untersuchung und Forschung 190, 3-8.

Grosch, W. \& Schieberle, P. (1991). Bread. In Volatile Compounds in Foods and Beverages, pp. 41-77 [H. Maarse, editor]. New York: Marcel Dekker.

Grosch, W., Zeiler-Hilgart, G., Cerny, C. \& Guth, H. (1993). Studies on the formation of odorants contributing to meat flavours. In Progress in Flavour Precursor Studies, pp. 329-342 [?. Schreier and P. Winterhalter, editors]. Carol Stream, IL: Allured Publishing Company.

Hurrell, R. F. (1982). Maillard reaction in flavour. In Food Flavours, pp. 399-437 [I. D. Morton and A. J. Macleod, editors]. Amsterdam: Elsevier.

Ishida, K. \& Kaji, Y. (1981). Effects of various additives on the volatile substances of cooked chicken. Nippon Shokuhin Kogyo Gakkaishi 28, 615-619. 
Kiely, P. J., Nowlin, A. C. \& Moriarty, J. H. (1960). Bread aromatics from browning systems. Cereal Science Today 5, 273-274.

Laksesvela, B. (1960). Supplementation of chick diets with vitamin E to improve meat quality. Journal of the Science of Food and Agriculture 11, 128-133.

Larick, D. K. \& Turner, B. E. (1990). Headspace volatiles and sensory characteristics of ground beef from forage- and grain-fed heifers. Journal of Food Science 54, 649-654.

Maarse, H. (1989). Volatile Compounds in Foods-Qualitative and Quantitative Data, 6th ed. Zeist: TNOCIVO Food Analysis Institute.

MacLeod, G. (1986). The scientific and technological basis of meat flavours. In Developments in Food Flavours, pp. 191-223 [G. G. Birch and M. G. Lindley, editors]. London: Elsevier.

MacLeod, G. \& Seyyedain-Ardebili, M. (1981). Natural and simulated meat flavors (with particular reference to beef). CRC Critical Reviews in Food Science and Nutrition 14, 309-437.

Marmer, W. N., Maxwell, R. J. \& Williams, J. E. (1984). Effects of dietary regimen and tissue site on bovine fatty acid profiles. Journal of Animal Science 59, 109-121.

Melton, S. L. (1983). Effect of forage feeding on beef flavor. Food Technology 37, 239-248.

Melton, S. L., Black, J. M., Davis, G. W. \& Backus, W. R. (1982). Flavor and selected chemical components of ground beef from steers backgrounded on pasture and fed corn up to 140 days. Journal of Food Science 47, 699-704.

Moody, W. G. (1983). Beef flavor-a review. Food Technology 37, 227-232.

Morrissey, P. A., Buckley, D. J., Sheehy, P. J. A. \& Monahan, F. J. (1994). Vitamin E and meat quality. Proceedings of the Nutrition Society 53, 289-295.

Morton, I. D., Akroyd, P. \& May, C. G. (1960). Flavouring substances. GB Patent no. 836694.

Mottram, D. S. (1987). Lipid oxidation and flavour in meat and meat products. Food Science and Technology Today 1, 159-162.

Mottram, D. S. (1991). Meat. In Volatile Compounds in Foods and Beverages, pp. 107-177 ([H. Maarse, editor]. New York: Marcel Dekker.

Mottram, D. S. \& Edwards, R. A. (1983). The role of triglycerides and phospholipids in the aroma of cooked beef. Journal of the Science of Food and Agriculture 34, 517-522.

Mottram, D. S. \& Madruga, M. S. (1993). The role of inosine monophosphate as a precursor of meat aroma. Proceedings of the 7th Weurman Flavour Research Symposium, Noordwijkerhout, The Netherlands (In the Press.)

Pippen, E. L. \& Nonaka, M. (1960). Volatile carbonyl compounds of cooked chicken. II. Compounds volatilized with steam during cooking. Food Research 25, 764-769.

Rhee, K. S. (1988). Enzymic and non-enzymic catalysis of lipid oxidation in muscle foods. Food Technology 42, 127-132.

Salter, L. J., Mottram, D. S. \& Whitfield, F. B. (1988). Volatile compounds produced in Maillard reactions involving glycine, ribose and phospholipid. Journal of the Science of Food and Agriculture 46, 227-242.

Saxby, M. J. (editor) (1993). Food Taints and Off-flavours. Glasgow: Blackie Academic \& Professional.

Shahidi, F., Rubin, L. J. \& D'Souza, L. A. (1986). Meat flavor volatiles: a review of the composition, techniques of analysis, and sensory evaluation. CRC Critical Reviews in Food Science and Nutrition 24, $141-243$.

van den Ouweland, G. A. M., Demole, E. P. \& Enggist, P. (1989). Process meat flavor development and the Maillard reaction. In Thermal Generation of Aromas, pp. 433-441 [Y. H. Parliment, R. J. McGorrin and C.-T. Ho, editors]. Washington, DC: American Chemical Society.

van den Ouweland, G. A. M. \& Peer, H. G. (1975). Components contributing to beef flavor. Volatile compounds produced by the reaction of 4-hydroxy-5-methyl-3(2H)-furanone and its thio analog with hydrogen sulfide. Journal of Agricultural and Food Chemistry 23, 501-505.

Whitfield, F. B., Mottram, D. S., Brock, S., Puckey, D. J. \& Salter, L. J. (1988). Effect of phospholipid on the formation of volatile heterocyclic compounds in heated aqueous solutions of amino acids and ribose. Journal of the Science of Food and Agriculture 42, 261-272.

Wong, E., Nixon, L. N. \& Johnson, C. B. (1975), Volatile medium chain fatty acids and mutton flavour. Journal of Agricultural and Food Chemistry 23, 495-498. 